\title{
Barium impaction therapy with balloon occlusion for deep colonic diverticular bleeding: a three-case series
}

Authors

Institution
Mikinori Koga, Chika Kusano, Takuji Gotoda, Sho Suzuki, Takemasa Sato, Masakatsu Fukuzawa, Takao Itoi, Fuminori Moriyasu

Department of Gastroenterology and Hepatology, Tokyo Medical University, Tokyo, Japan submitted:

7. July 2015

accepted after revision:

8. February 2016

\section{Bibliography}

DOI http://dx.doi.org/

10.1055/s-0042-103237

Published online: 15.4.2016

Endoscopy International Open

2016; 04: E560-E563

(c) Georg Thieme Verlag KG

Stuttgart - New York

E-ISSN 2196-9736

\section{Corresponding author}

Chika Kusano, MD PhD

Department of

Gastroenterology and

Hepatology

Tokyo Medical University

6-7-1 Nishishinjuku

Shinjuku-ku

Tokyo 160-0023

Japan

Fax: +81-3-53816654

ckusano2007@yahoo.co.jp
Background and aims: In hemostasis for colonic diverticular bleeding, the incidence of recurrent bleeding is higher in deep colonic diverticulum than in shallow. We aimed to improve and evaluate barium impaction therapy using an enteroscopic overtube with balloon.

Patients and method: We performed barium impaction therapy in three patients with a diagnosis of deep colonic diverticular bleeding. The tip of the overtube was inserted to reach the cecum using the conventional method. After deflating

\section{Introduction \\ $\nabla$}

Colonic diverticular bleeding is among the most common diseases with lower gastrointestinal bleeding [1]. Endoscopic hemostasis [2], interventional radiology [3], and surgical treatment [4] are reportedly effective for controlling colonic diverticular bleeding. However, achieving hemostasis is often difficult with these methods when the bleeding source is uncertain. Barium impaction therapy was reported to be an effective alternative [5]. However, with this method, which does not require identification of a diverticulum responsible for bleeding, it is often difficult to apply pressure to the deep colon (right-sided colon). The deep colon is filled with barium by changing body positions. Therefore, the internal intestinal pressure required for the impaction to achieve hemostasis may not be produced.

We report a novel technique using an enteroscopic overtube with balloon, which allows sufficient barium filling while applying pressure to the diverticulum.

\section{Patients}

\section{$\nabla$}

Among patients who visited our hospital with the chief complaint of bloody stools and who were diagnosed as having colonic diverticular bleeding the colon, the enteroscope was removed. The balloon in the tube was inflated, followed by barium filling via the tube. Sufficient pressure was applied by ensuring no regurgitation into the small intestine side. The entire colon was continuously filled with barium in stages.

Results: Post-treatment bleeding was controllable without adverse events in all three patients.

Conclusion: This novel barium impaction therapy using an enteroscopic overtube with balloon was effectively performed without adverse events.

from the deep colon by exclusion, three with poorly controlled bleeding during hospitalization were administered a novel technique ( $\bullet$ Table 1 ). For diagnosis, upper and lower gastrointestinal endoscopy and contrast-enhanced computed tomography (CT) were concurrently performed. Diverticular bleeding from the deep colon was diagnosed by exclusion in patients meeting all of the following criteria: lower gastrointestinal endoscopy revealing diverticula and fresh clots in the deep colon, failure to confirm bleeding from a responsible diverticulum and to provide definitive diagnosis, detection of brown stools in the small intestine to exclude small intestinal bleeding, and indication of the absence of mucosal lesions that could cause bleeding, such as angiectasis, inflammation, and ulcers of the colonic mucosa. The upper gastrointestinal endoscopy excluded upper gastrointestinal bleeding, and contrastenhanced CT could not identify the responsible blood vessel. Deep colonic diverticular bleeding was considered if spontaneous hemostasis had been achieved before observation. Moreover, in these three patients, neither endoscopic treatment nor interventional radiology was performed because the bleeding source was difficult to identify with endoscopy and contrast-enhanced CT. 


\begin{tabular}{|llllll|}
\hline Case no. & Age, years & Sex & Comorbidity & Medication & $\begin{array}{l}\text { Location of } \\
\text { diverticulum }\end{array}$ \\
\hline 1 & 80 & M & $\begin{array}{l}\text { Prostatic cancer } \\
\text { AP } \\
\text { HT }\end{array}$ & L-Asp \\
\hline 2 & F & $\begin{array}{l}\text { RA } \\
\text { HT } \\
\text { HL }\end{array}$ & NSAIDs \\
\hline 3 & 64 & M & $\begin{array}{l}\text { MR (post MVR operation) } \\
\text { HT } \\
\text { HU }\end{array}$ & $\begin{array}{l}\text { NSAIDS } \\
\text { L-Asp } \\
\text { Anticoagulants }\end{array}$ & TO \\
\hline & & & AC/SC \\
\hline
\end{tabular}

Table 1 Demographic and clinical data for patients undergoing therapeutic barium enema for diverticular bleeding.

\begin{tabular}{|c|c|c|c|c|c|}
\hline $\begin{array}{l}\text { Author/s (year) } \\
\text { [Reference] }\end{array}$ & $\mathbf{n}$ & Location & $\begin{array}{l}\text { Concentration of } \\
\text { barium used, w/v\% }\end{array}$ & $\begin{array}{l}\text { Successful } \\
\text { cases }\end{array}$ & $\begin{array}{l}\text { Recurrent } \\
\text { bleeding }\end{array}$ \\
\hline Adams (1970) [10] & 28 & NR & 20 & 26 & 9 \\
\hline Chorost et al. (2001) [9] & 1 & TO & 20 & 1 & 0 \\
\hline $\begin{array}{l}\text { Koperna et al. (2001) } \\
\text { [11] }\end{array}$ & 63 & NR & NR & 53 & 10 \\
\hline $\begin{array}{l}\text { Matsuhashi et al. } \\
(2003)[8]\end{array}$ & 1 & TO & $\begin{array}{l}200 \text { (with } 1 \mathrm{mg} \text { of } \\
\text { epinephrine) }\end{array}$ & 1 & 0 \\
\hline $\begin{array}{l}\text { Iwamoto et al. (2008) } \\
\text { [12] }\end{array}$ & 4 & $\begin{array}{l}\text { TO, } \\
\text { AC,SC( } 2 \text { cases })\end{array}$ & 200 & 4 & 0 \\
\hline $\begin{array}{l}\text { Fujimoto et al. (2011) } \\
\text { [16] }\end{array}$ & 11 & NR & 60 & 11 & 6 \\
\hline $\begin{array}{l}\text { Niikura et al. (2013) } \\
\text { [13] }\end{array}$ & 1 & $A C$ & 200 & 1 & 0 \\
\hline Nagata et al. (2015) [5] & 27 & $\begin{array}{l}\text { Right-sided: } 7 \text { cases } \\
\text { Left-sided: } 5 \text { cases } \\
\text { Bilateral colon: } 15 \text { cases }\end{array}$ & 200 & 27 & 5 \\
\hline Our cases (2015) & 3 & $\begin{array}{l}\text { AC,SC } \\
\text { TO } \\
\text { AC,SC }\end{array}$ & 200 & 3 & 0 \\
\hline
\end{tabular}

Table 2 Previous reports on therapeutic barium enema for diverticular bleeding.

TO, throughout the colon; AC, ascending colon; TC, transverse colon; DC, descending colon; SC, sigmoid colon; NR, not reported; Right-sided, transverse or proximal colon; Left-sided, descending or distal colon; Bilateral colon, around the entire colon.

\section{Methods}

All three patients had achieved spontaneous hemostasis at the time of this study. The treatment was performed to prevent recurrent bleeding.

An enteroscope (SIF TYPE Q260, OLYMPUS, Tokyo, Japan) with an overtube (single-use splinting tube, OLYMPUS) ( $\bullet$ Fig. 1) was in-

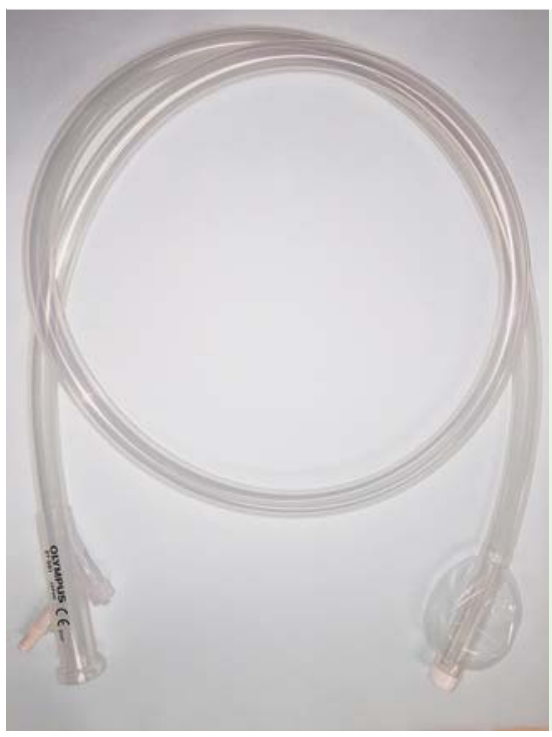

serted, and the scope was removed when the tube reached the cecum ( $\bullet$ Fig. 2a).

An enema catheter (double balloon enema catheter with 3-pipe isolation check valve; Kaigen Pharma Co., Ltd., Osaka, Japan) was connected to an overtube, and the balloon was initially inflated around the midpoint between the cecum and the hepatic flexure to close the colon cavity. High-density barium 200 w/v\% was then injected ( $\bullet$ Fig. 2b). The intestinal tract was filled with barium and was sufficiently pressurized for 3 minutes without regurgitation into the small intestine side. The balloon was subsequently inflated at sites equally dividing the total colon into eight parts, with filling and maintaining being repeated in stages, eventually filling the entire colon ( $\bullet$ Fig. $2 c, \bullet$ Fig.2d, $\bullet$ Fig. 2e).

\section{Results}

$\nabla$

In all three patients, the entire colon could be filled with a total volume of barium of about $1200 \mathrm{~mL}$ to $1500 \mathrm{~mL}$ without adverse events such as perforation. Abdominal radiography on the day following treatment showed barium remnants in the diverticulum ( Fig.3). All three patients had favorable courses with control of bleeding after treatment. Barium in the intestinal tract outside the diverticulum was excreted without additional laxatives, with no ileus symptoms, diverticulitis, or appendicitis. 

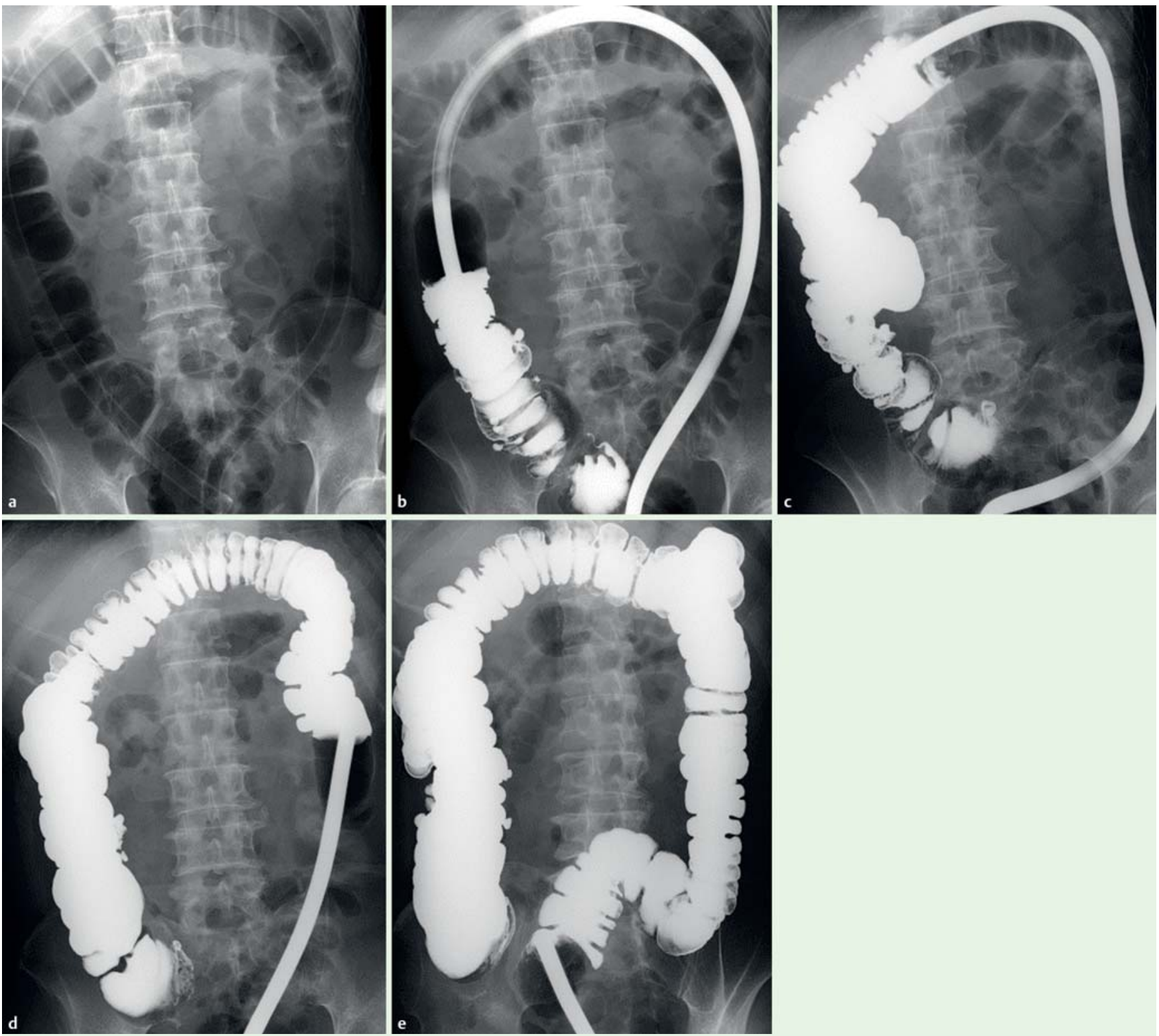

Fig. 2 a Overtube inserted into the cecum. b Balloon inflated in the ascending colon at the midpoint between the cecum and hepatic flexure, followed by barium filling. $\mathbf{c}$ Filling from the midpoint of the transverse colon. $\mathbf{d}$ Filling from the midpoint of the descending colon. $\mathbf{e}$ Barium filling of the entire colon completed.

\section{Discussion}

$\nabla$

Cases of colonic diverticulosis are increasing annually [6], resulting in more cases with diverticular diseases [7]. The endoscopic identification rate of diverticular bleeding sources was reportedly $38 \%$, the hemostasis rate $88 \%$, and the recurrent bleeding rate $22 \%$ [8].

Several reports have described the usefulness of barium impaction therapy, which is an option for patients whose bleeding source cannot be identified ( Table 2) [2,8-13]. However, recurrent bleeding rates with barium impaction therapy and endoscopic treatment were similar [14]. The rate of recurrent bleeding from deep colonic diverticulum is higher than with endoscopic treatment. One explanation is the difficulty in applying pressure to the deep colon with the conventional method of barium impaction via the rectum. Although there is no clear evidence of the hemostatic mechanism of barium impaction, various effects have been reported, such as a tamponade action, direct blood clotting, mucosal protection, and exposed blood vessel clotting $[2,12,15]$. Regarding the concentration of barium, previous studies used concentrations ranging from $20 \mathrm{w} / \mathrm{v} \%$ to $200 \mathrm{w} / \mathrm{v} \%$ $[2,5,8-13]$. We used a concentration of $200 \mathrm{w} / \mathrm{v} \%$ in this study, although we were uncertain about whether a higher concentration barium impaction could provide better results because there were no studies on this issue. Further studies investigating the hemostatic mechanism of barium impaction as well as the optimal concentration for the treatment are required.

In contrast to the conventional method, pressure is directly applied to the deep colon via barium filling under balloon occlusion. The tamponade effect of barium is apparently enhanced, thereby increasing the hemostasis effect. The disadvantages include possible increased risk of perforation due to pressurization. We adjusted the barium injection pressure so that barium did not pass back through the ileocecal valve into the small intestine, as regurgitation of barium into the small intestine side might lead to decreased pressure in the large intestine. These three patients re- 


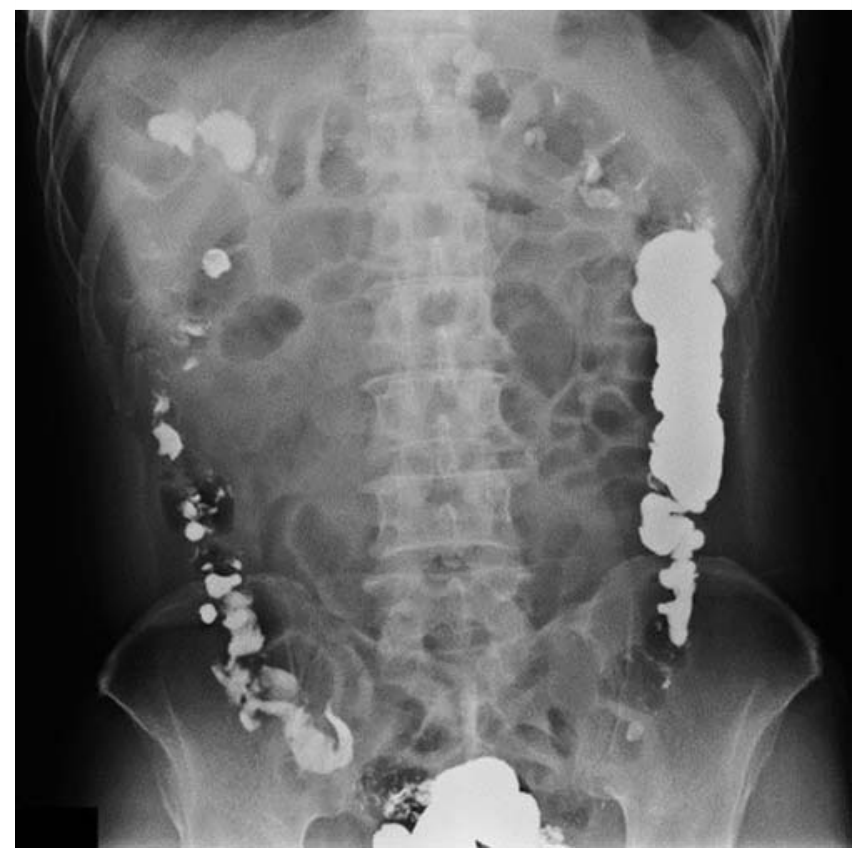

Fig.3 Abdominal radiography on the day following treatment showing barium remnants in the diverticulum.

ceived barium impaction therapy using an enteroscopic overtube with balloon after endoscopy to rule out intestinal mucosal damage due to Crohn's disease, ulcerative colitis, ischemic enteritis, intestinal tuberculosis, intestinal Behcet's disease, or infectious enteritis.

Ensuring safety will be one of the future challenges since no evidence is available to support the association between intestinal pressure and perforation. The perforation risk will increase in patients with these intestinal disorders because their affected mucosae will be more fragile than normal mucosae. Ileocecal valve deformity may be detected depending on the type of disease diagnosed. The pressure from barium impaction may not extend to the small intestine in patients with valve deformity, and as a result of this pressure, the colon may perforate. Therefore, barium impaction therapy with an enteroscopic overtube with balloon should not be used in patients in whom an intestinal disorder causing mucosal damage was detected using endoscopy or those with an ileocecal valve deformity. Moreover, although it seems that more diverticula can be filled with barium by the application of pressure than by using the conventional method, it can be expected that the application of pressure simultaneously increases the risk of diverticulitis. Even in patients in whom this method is performed and whose abdominal pain, fever, and other symptoms suggest diverticulitis, we have to diagnose the condition without a CT scan, because the presence of barium in the intestinal tract causes the appearance of artifacts, making diagnosis with CT extremely difficult. Other disadvantages are the requirement for an enteroscope, which is not widely available in general hospitals, the relatively high cost of the overtube, and the greater manpower requirements for the procedure.
The limitation of this novel technique is no evidence of its therapeutic effects in this case series, which describes only three cases. Although this technique may significantly increase the risk of complications in comparison to the conventional method, it should provide more benefits than risks through its therapeutic effects on hemostasis and long-term prevention of recurrence.

Further studies are needed to improve the method and establish evidence of treatment effectiveness. A prospective comparative study is required to validate long-term recurrence prevention rates and the safety of this novel barium impaction therapy technique.

AP, angina pectoris; HT, hypertension; RA, rheumatoid arthritis; HL, hyperlipidemia; MR, mitral regurgitation; MVR, mitral valve replacement; HU, hyperuricemia; NSAIDs, nonsteroidal anti-inflammatory drugs; L-Asp, low-dose aspirin; TO, throughout the colon; AC, ascending colon; SC, sigmoid colon.

\section{Competing interests: None.}

\section{References}

1 Varnava AM3rd, Moore BA, Longo WE et al. Lower gastrointestinal bleeding. Dis Colon Rectum 1997; 40: 846-858

2 Jensen DM, Machicado GA, Jutabha $R$ et al. Urgent colonoscopy for the diagnosis and treatment of severe diverticular hemorrhage. NEJM 2000; 342: $78-82$

3 Khanna A, Oqnibene SJ, Koniaris LG. Embolization as first-line therapy for diverticulosis-related massive lower gastrointestinal bleeding: evidence from a meta-analysis. J Gastrointest Surg 2005; 9: 343-352

4 Mayakel JA, Opelka FG. Colonic diverticulosis and diverticular hemorrhage. Clin Colon Surg 2004; 17: 195 - 204

5 Nagata $N$, Niikura R, Shimbo T et al. High-dose barium impaction therapy for the recurrence of colonic diverticular bleeding. Ann Surg 2015; 261: $269-275$

6 Miura S, Kodaira S, Shatari T et al. Recent trends in diverticulosis of the right colon in Japan: retrospective review in a regional hospital. Dis Colon Rectum 2000; 43: 1383-1389

7 Nakada I, Ubukata H, Goto Y et al. Diverticular disease of the colon at a regional general hospital in Japan. Dis Colon Rectum 1995; 38: 755 759

8 Matsuhashi N, Akahane M, Nakajima A. Barium impaction: a therapy for refractory colonic diverticular bleeding. AJR Am J Roentgeno 2003; 180: 490 - 492

9 Chorost MI, Fruchter G, Kantor AM et al. The therapeutic barium enema revisited. Clin Radiol 2001; 56: 856 -858

10 Adams JT. Therapeutic barium enema for massive diverticular bleeding. Arch Surg 1970; 101: 457-460

11 Koperna T, Kisser M, Reiner G et al. Diagnosis and treatment of bleeding colonic diverticula. Hepatogastroenterology 2001; 48: 702 - 705

12 Iwamoto J, Mizokami Y, Shimokobe $K$ et al. Therapeutic barium enema for bleeding colonic diverticula: four case series and review of the literature. World J Gastroenterol 2008; 14: 6413-6417

13 Niikura R, Nagata N, Yamano Ket al. High-dose barium impaction therapy is useful for the initial hemostasis and for preventing the recurrence of colonic diverticular bleeding unresponsive to endoscopic clipping. Case Rep Gastrointest Med 2013; 2013: 365954

14 Ishii N, Setoyama T, Deshpande GA et al. Endoscopic band ligation for colonic diverticular hemorrhage. Gastrointest Endosc 2012; 75: 382 387

15 Miller RE, Skucas J, Violante MR et al. The effect of barium on blood in the gastrointestinal tract. Radiology 1975; 117: 527-530

16 Fujimoto A, Sato S, Kurakata S et al. Effectiveness of high-dose barium enema filling for colonic diverticular bleeding. Colorectal Dis 2011; 13 : $896-898$ 